\title{
Regulatory Authority Effective Date Range
}

National Cancer Institute

\section{Source}

National Cancer Institute. Regulatory Authority Effective Date Range. NCI Thesaurus.

Code C94054.

The date and time span for when the regulatory authority is active. 